\title{
E-Commerce Platforms and Supply Chain Management - Functionalities Study
}

\section{Nikolay Dragomirov*}

\section{Abstract}

The rise of e-commerce worldwide represents an indisputable and sustainable process of transformation of previously known market relationships. It has led to the development and continuous improvement of a number of processes related to the efficient management of material flows in the supply chain. E-commerce platforms can in general be considered as specialised software solutions that, in addition to presenting products in digital space, can play a significant role in organising logistics, marketing and financial processes. This complex logistics management problem can be studied through several indicators related to integration of the inner supply chain and to the management of relationships with product suppliers, buyers and trade partners, and logistics services providers. The article outlines the results of a study of the logistics functionalities of some leading e-commerce platforms and reveals some trends in their evolution and their readiness for supporting some of the supply chain management processes.

Keywords: SCM, logistics, e-commerce JEL: M15, M19

\section{Introduction}

Two decades ago, e-commerce was quite an exotic undertaking, but since then it has become familiar and widespread all over the world, and today it is a real alternative to classic trading processes. There is a strong trend of transformation of online shopping into a sustainable practice for many consumers in Europe and around the world. Now, e-commerce is growing mainly because of the increased internet access, but this is not the only reason and there are other factors. Some of these are the increased proportion of buyers who are using mobile phones to access the internet and the fact that the main volume of e-commerce trade comprises small orders (PostNord, 2017). These facts are important because they affect the parameters of modern e-commerce. Now, customers have complete freedom when they do their shopping and they can send and receive their orders in any way they prefer. Any other business model is inadequate. There are some quantitative measurements of the e-commerce market that could be discussed. In the EU-28 (European Union of 28 countries), during the period 2008 to 2016 , the percentage of enterprises that had e-sales increased by $7 \%$ and company turnover realised from e-sales increased by $6 \%$ (Eurostat 2017). Unfortunately, there is a wide variance in the proportion of e-sales among

University of National and World Economy - Sofia, Department of Logistics and Supply Chains 


\section{Articles}

countries and in the proportion of enterprises conducting e-sales and in the turnover from e-sales according to enterprise size - small, medium and large (Eurostat, 2017).

\section{E-commerce Platforms}

This process of market transformation cannot be implemented without e-commerce platforms that are responsible for the automation of a lot of trade and customer service functions. They make it possible for digital marketplaces to work 24 hours a day and seven days a week, even without human support. However, this is not enough for a successful business model; an adequate supporting infrastructure for the management of the logistics activities is needed to ensure the movement of the material flows (Dragomirov, 2014) in the supply chain. It is important to mention that e-commerce is not just a new distribution channel; it is a change which in a revolutionary way impacts warehousing processes and inventory management (Żurek, 2015).

Clearly, easy internet access and users having the necessary devices are very important but there is something else which can solve the problems related to the management of the virtual marketplace. It can be done by the information platform for the e-commerce that connects the buyer and the seller in the digital space. Then we can go further with the management of real processes, mainly the logistics of material flows. E-commerce platforms are information products that give the sellers solutions to offer their products and services in the digital space, and if there is interest expressed by the buyer to support the selling process by closing the sale and finishing the transaction. The availability of products and services in e-commerce makes customers change their preferred form of trading and choose internet sales (Kadłubek, 2015). In practice, there are hundreds of solutions to do that and it is impossible to cover the variety of all platforms. In general they can be classified according to several criteria, mainly by the functionality of the platform and the ownership of the supporting infrastructure. The e-commerce solutions can be classified as (Retail Sector Group of Enterprise Europe Network, 2018, pp. 11-13):

- Open-source e-commerce software and self-hosted platforms.

- Hosted e-commerce platforms.

- E-marketplaces.

In the first two cases the seller has his own domain name, which is redirected to a hosting account where the software solution is physically located. There are plenty of software products based on this principle. The opensource platforms are particularly important due to their numerous advantages. Some of them are WordPress and Joomla that can be used to create fully functional e-commerce platforms by upgrading with additional cart plugins to add functionalities for transaction processing, for example, the former platform can be upgraded with WooCommerce and the second one with Virtuemart. There are also many software alternatives which are fully operational solutions and they are not based on this upgrade principle. They are tightly focused on e-commerce and in their basic installations cover the main trading processes. For instance, we could mention Magento, PrestaShop, Opencart etc.

The last alternative for e-business is to use an e-marketplace where the seller can find everything needed. In this case the information infrastructure is already built and the seller uses the solution in most cases as it is, without customisation or any adoptions for his business model needs. A popular example of this approach is Ebay. No domain name and hosting account is needed; the only requirement is that a transaction fee is 


\section{Articles}

paid for a real order received. Also the selling process is protected by the privacy and legal regulations in the different countries. All of these functionalities are included and offered to the online seller.

There are other interesting aspects of e-commerce sales. One of them is the ability to add selling capabilities to any website that has no selling cart functionalities. This process is usually simple and adoptable for any website, but unfortunately it has many limitations. One of these popular solutions is giving online sellers the ability to add selling functions to (BigCommerce Pty., 2019a):

- Facebook, Instagram and Google shopping.

- Any web page by adding buy buttons.

In fact it is possible to find the most appropriate solution for every specific business need and for any trading case. It could be mentioned that there is a trend towards the integration of many sales channels into one platform, as seen in the integration possibilities of Ebay, Amazon, Facebook, online messengers, points of sale etc., which are common functionalities for the leading platforms, such as Shopify (Shopify, 2019). It could be questioned whether platforms that resemble free classified ads and do not process transactions, but also offer functionality related to the preparation of bills of lading to courier organisations, which is a form of integration with a logistics service provider. Another very forward-looking and promising trend in e-commerce is using an outsource fulfilment service, which usually minimises the costs associated with logistics and can allow more time to be dedicated to marketing, branding, etc. (Kawa, 2017). In this case the company outsources the logistics to another company, and this form of collaboration is not covered by the current research.
E-Commerce Platforms and Supply Chain Management Functionalities Study

Nevertheless, the different types of e-commerce platforms are important for many logistics and supply chain management activities including these for the internal and external supply chains. This approach for dividing the supply chain into internal and external supply chains is used in different research frameworks (Rakovska, 2011; Rakovska, Stratieva, 2018) and in all of these parts of the supply chain the management of the information flow for management of material flow is a metric for the level of supply chain management integration. Information is a key element that holds together the structure of all businesses (Evans, Wurster, 1997). Supply chain management is an important evolution stage of the competition and could be reviewed as the management of upstream and downstream relationships with suppliers and customers in order to deliver superior customer value at less cost to the supply chain as a whole (Christopher, 2011, p.3). The e-commerce platforms are also a significant resolution to the appearance problems of digital firms. These companies could be defined: in which nearly all of the organisation's significant business relationships with customers, suppliers, and employees are digitally enabled and mediated, and core business processes are accomplished through digital networks spanning the entire organisation or linking multiple organisations (Laudon, 2013, p.41). In many practical cases the main collaborative processes for these companies and the other supply chain members can be managed through e-commerce platforms.

\section{Methodology}

The main purpose of the article is to research the current status of the leading e-commerce platforms and to evaluate their ability to integrate logistics and supply chain management processes. The research 


\section{Articles}

covers mainly the platforms designed for selfhosting and maintenance without covering the complete solutions offered as SaaS (Software as a Service). The selection of the e-commerce platforms to include in the research is based on analysis of the platform's market share in the web space (BuiltWith 2019; Statista 2017). The research focus is set on the main platforms that cover more than $50 \%$ of web shops in the digital space. These are:

- Magento

- Opencart

- Prestashop

- Virtuemart/Joomla

- Woocommerce/Wordpress
Each solution was installed in a hosting account covering the system requirements for these products - PHP up to 7.2, MySQL up to v.5.7 (MariaDB v10.2), 50GB disc space, 1GB RAM and $3000 \mathrm{~min} / \mathrm{m}$ CPU time. The functionality of the products was studied by considering different indicators related to the internal and external supply chain management covered by the e-commerce platform: 1) Customer relationship management; 2) Relationship management with trade partners; 3 ) Integration with logistics service providers; 4) Integration with payment systems; 5) Relationship management with suppliers and 6) Integration of internal supply chain processes as represented in Figure 1. The research was conducted at the end of 2018.

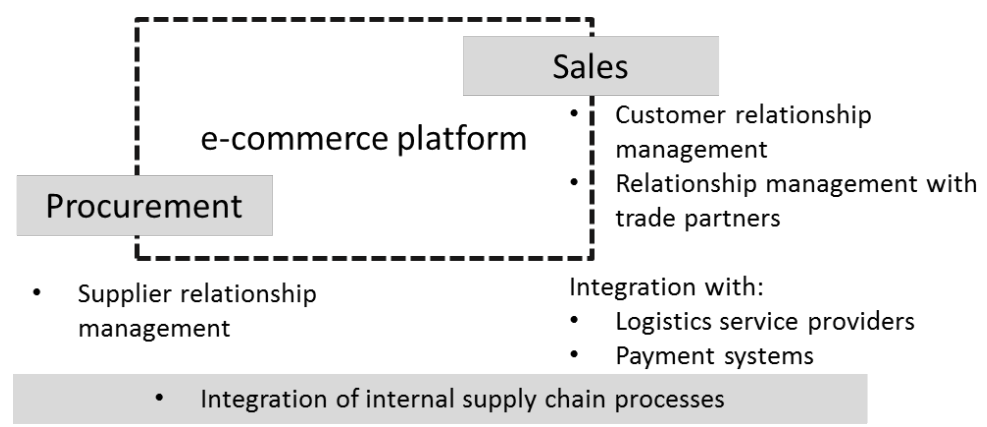

Figure 1. Research framework for e-commerce platforms and supply chain management

For the customer relationship management indicator there are two important interfaces logistics and marketing. While marketing includes analysis of markets, product development, communication and sales, logistics must ensure that materials flow in an efficient way along the supply chain, complying with customer requirements, at reduced cost (Dragomirov 2015) and the marketing and logistics interaction is very important for the success of the business organisation. In the current research the focus is mainly directed towards the logistics and supply chain management side and this reveals alternatives for future research projects on the marketing side of the problems and for integration with payment systems.

The research also considers an important aspect of e-commerce platform customisationthe availability of extensions for upgrading the systems. Most of the solutions offer a central database to find appropriate software and some of them reveal the number of active installations. This metric discovers the extension popularity within the online stores, which is relevant to the real market needs for such solutions. 


\section{Articles}

\section{Results and Discussion}

After conducting a detailed study of the covered e-commerce platforms, it is possible to conclude in general that they cover the main processes for e-commerce. This is the reason why they have a leading position in the market. Although there are several variations in the functionality of the different platforms, there are also some common trends in their evolution.

\section{Customer Relationship Management}

Each of the platforms, including the different upgrade versions, is mainly focused on the sales and customer relationship management - these are core elements. All of them can represent products in the virtual space and they can process transactions. Their evolution and functionality improvement is a significant milestone which is a result of common technical trends such as using mobile devices, social media integration and mixed-reality (Augment, 2016). An important alternative for the platforms is the possibility to upgrade every solution using plugins/extensions. This gives a great opportunity to the seller to add other additionally needed functionality. This is important because the extension market offers thousands of alternatives for customisation. For WooCommerce, for example, there are thousands of active plugins on the market and some of them have thousands of real installations. With these upgrade options, every e-commerce platform could be transformed into a fully functional customer relationship management system. The plugins market is very competitive and this makes it possible for every seller to customise the platform in the needed way. This freedom to upgrade with many alternatives is very common for all open-source solutions, where the user is totally independent on the software developer and there are also other benefits related to the lower budgets for development,
E-Commerce Platforms and Supply Chain Management Functionalities Study

better security, following new trends, etc. (Hill 2017; Noyes, 2010).

Definitely all the solutions in the e-commerce platforms market can satisfy most of the needs of online sellers. Also, they are able to cover the variety of problems encountered in the different evolution stages of e-commerce in a business organisation (Dragomirov, 2014, p. 254) as represented in Figure 2. They are able to represent products and services, process orders, achieve integration with logistics service provides and finally integration with suppliers.

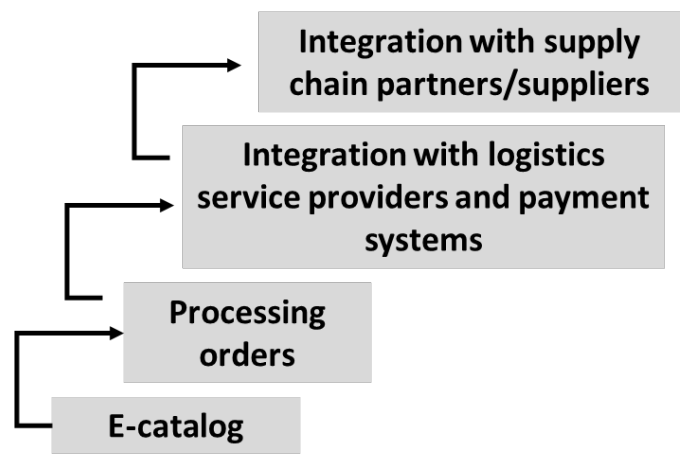

Figure 2. E-commerce evolution within the organisation

This model reveals strong potential for expanding the logistics activities that can be integrated and automated by the e-commerce platform. In the first stages, the organisation point of view and focus on e-commerce is traditional, and the software is used only to represent the products like in an e-catalogue, and for processing transactions. In the future stages the organisation will look for better efficiency in the supply chain activities, mainly regarding backward integration with the product suppliers. Presenting products is an important basic functionality for all of the researched platforms. They do so by classification of products into categories and they also add the ability to process customers' orders for these products. In the basic installations of the platforms, there are no 


\section{Articles}

significant differences between the platforms for the product' presentation, but for the orders we can find variations, usually related to user registration, anonymous orders, one click checkout, wish lists, etc.

\section{Relationship Management with Trade Partners}

A specific functionality evolution is when the e-commerce platform is integrated with other platforms and the purpose is to reach more potential customers. This is innovative partnership in the supply chain which is based on different practices for information integration, usually called drop-shipping. As a result these integrated platforms process the customers' orders and they trigger the movement of the material flows in the supply chain. These partners work only with data and information and they do not have direct access to the management of the material flows in the supply chain. These cases could be described as customer service activities that could be carried out by other supply chain partners (Hayes, Youderian, 2013, p.8). The benefits of this approach of collaboration are many, and the e-commerce platforms can be upgraded to support the data and information interchange. Unfortunately, in practice, e-mails are widely used because of their simplicity but they can offer only transactional exchange which has many negative aspects and is not an efficient solution in modern logistics.

\section{Integration with Logistics Service Providers and Payment Systems}

Integration with logistics service providers is very important for the logistics management because it is related to the management of the physical material flows in the supply chain to ensure that the product will reach the customer. Today, when the internet markets are growing and they are very competitive, there are many delivery practices, especially in the final stage that is called Last-mile Logistics. This is a part of the supply chain which links directly to the end user, and according to the results of logistics activity the consumer assesses logistics services that he receives from both his supplier and the entire supply chain (Kochubei, Lysa, 2018). The main alternatives in the distribution channel could be classified as (Lim, Srai, 2015):

- Push-Centric System: N-Tier Direct to Home.

- Pull-Centric System: Customer SelfHelp - taking the delivery from a collection point.

- Hybrid system - N-Tier to Customer Self-Help Location.

For the self-service systems there is an important alternative - using parcel lockers that reshape the delivery and return process and create value for the customer (Vakulenko et al., 2018). These automated systems give a variety of benefits and opportunities for improving the delivery and return processes and they could be seen as marking the beginning of automated delivery systems.

After receiving the order an important task is to ensure the on-time delivery because the success of the online seller is correlated with the logistics capabilities to do that (Wu, Lin, 2018). For some product groups such as FMCG (fast moving consumer goods), although they currently represent a relatively low proportion of the e-commerce market (Nielsen, 2017), the delivery process is the main objective and challenge (Saskia et al., 2016). Also, in e-commerce the consumer behaviour is dynamic, which motivates sellers to develop Omni-channels (multi-channel sales) which provides easy switching between online and offline (Kateva, 2017). These channels are working with each other (Atanasov, 2016) and multichannel retailers are more efficient in logistics than pure players (Zeng, Bolz, 2017). 


\section{Articles}

The usual delivery practice is to deliver to the customer's preferred location using a logistics service provider. In that case the integration with this partner is very important because there are several alternatives for communication, especially for the generation of the postage label. It can be done manually or automatically. In both cases the order details about the recipient must be sent to the logistics service provider, but with the former method, human interaction is needed, which results in more time and more possibilities for errors, while with the latter method we have fully automatic communication between the two systems which is fast, efficient and error free. When receiving a new order, the e-commerce platform can communicate with the logistics service provider systems for obtaining actual delivery costs and when the order is fulfilled it can send all of the data needed to ensure the delivery process proceeds smoothly.

For the research indicator integration with logistics service providers and payment systems it is possible to conclude that the e-commerce platforms are very flexible because they offer a variety of alternatives for upgrade. They can be extended with many additional functionalities for collaboration with logistics service providers and payment systems. In the basic installations there are mainly alternatives for working with global leaders like UPS, FEDEX, PAYPAL etc. but using an API (Application Programming Interface) they can be integrated with any other system. APIs allow different groups of developers, both internal or external, and partners to gain access to enterprise systems in a simple way (HCL, 2014). In practice the local logistics service providers develop free extension modules for the most popular e-commerce systems to integrate them within their systems.
E-Commerce Platforms and Supply Chain Management Functionalities Study

\section{Supplier Relationship Management}

Certainly, only order processing and integration with trade partners and logistics service providers is not enough for success. Modern competition has created new business rules for efficient logistics and material management in the supply chain. This explains why some of the platforms have focused on efficient inventory management and supplier relationship management. As regards this functionality none of the e-commerce platforms are very well organised in their basic installations, which is common for the other research indicators mentioned in the article. A positive aspect is that this functionality can be added if it is necessary to satisfy the logistics needs. For the Magento platform, for example, it is possible to find a complete solution that covers functionalities such as managing suppliers and assigning products to them, sending product quotations, creating orders, tracking orders, managing payment methods used to work with supplies etc. (Magestore, 2019). These features of the software give the Magento e-commerce platform a functionality that is typical of enterprise resource planning software (ERP).

Another example of such integration of logistics functions and transformation into ERP systems is the platform Prestashop which can be upgraded through many modules named Third-party Data Integration CRM (Customer relationship management) and ERP (Enterprise resource planning) (Prestashop, 2019). When following this approach for upgrading and integrating the systems the possible solutions are endless and the price is the greatest benefit the store owners receive. There are plenty of other examples and they differ according to the business model of the developer. The important conclusion here is that in the future, e-commerce platforms will be better prepared for integration with other information systems and technologies 


\section{Articles}

because the future will see high usage of connected networks such as the loT (Internet of Things), Big Data analyses and cloud technologies (Yu et al., 2016). From a logistics point of view the link between material and information flows throughout the chain is of paramount importance (Rakovska, Stratieva, 2018). This future will require massive data and information interchange between the supply chain participants for efficient material management, which is a typical external supply chain integration practice.

The informational integration of the information systems of the supply chain members is definitely a prerequisite for supply chain management. This is an important evolution stage because successful supply chain management requires cross-functional integration within the firms and across the networks that comprise the supply chain (Lambert, 2008). Some of the most integrated areas in the business reality now are CRM and ERP systems, logistics services and payment gateways, client portals, Point of Sale (POS), and Electronic Data Interchange (EDI) solutions (Cross, 2018; Pirinsky, 2018). Collaboration and information integration is important also for the outsourcing of logistics activities such as inventory management and order shipping. Once a customer makes a purchase, the outsource partner information systems will know and they can send the package out quickly (BigCommerce Pty. $2019 b$ ). All of this means that there is additional potential for building more competitive models based on information systems. An important problem for the information integration is the level of automation; unfortunately not all e-commerce platforms are ready for this because many of the integration models require human assistance and management but this could be defined as a potential area for future development.

\section{Integration of Internal Supply Chain Processes}

In the context of supply chain management, logistics serve to move and position inventory to achieve desired time, place, and possession benefits at the lowest total cost (Bowersox et al., 2002). To do that the related logistics activities are: (1) order processing; (2) inventory; (3) transportation; (4) warehousing, materials handling, and packaging; and (5) facility network design (Bowersox et al., 2002). Some of the order processing problems were discussed previously in the research. For the integration of the internal supply chain processes research indicator from the point of view of e-commerce platforms, the main research areas are transport management, warehousing and inventory management.

The main conclusion for the internal supply chain integrations is that the functionalities of e-commerce platforms are not sufficiently developed for the management of transport, warehousing and inventory activities. Again the focus of the platforms is generally on the process of presentation of the products and receiving orders. If any functionality for integration of internal supply chain processes is available in the basic installation version, in most cases it needs to be upgraded by the installation of extension modules. Unfortunately, it is not so easy to do that because the market for such logistics solutions is not very large and there are only a limited number of plugins with restricted functionalities, which is not the case for marketing solutions where the market offers hundreds of alternatives. For Woocommerce the number of inventory management plugins is very low percentage of the overall number of active plugins according to the data on the installations, although it is common for the other platforms.

In practice, for the warehousing processes the e-commerce platforms rely mainly on 


\section{Articles}

ERP and WMS (warehouse management system) software integration. Nevertheless, on the extension market there are extension solutions mainly for order picking, and they cover simple problems such as printing picking lists and integration of information technologies for automatic identification mainly printing barcodes. The reason for that is that the most important selection criterion for warehousing systems in e-commerce is picking performance (Boysen et al., 2018) and picking is associated with the highest proportion of warehousing costs (Richards 2014).

To solve the problems related to the integration of internal supply chain processes on the e-commerce solutions market there are several trendy software solutions that specialise in integrating the world's biggest e-commerce platforms, marketplaces, shipping couriers, and accounting platforms (Veeqo, 2018), and their features cover a variety of warehousing activities and problems, including multiple warehouses,
E-Commerce Platforms and Supply Chain Management Functionalities Study

product location, automatic identification etc. Using these types of solutions for information collaboration is safe for the online seller because the entire logistics process is controlled by a single information point.

For transport problems in logistics the e-commerce platforms are relying more and more on integration with other software products, which is reasonable. The seller can use API integration or other database export of the customers' locations and their orders to plan and organise deliveries. The reason for this is that the proportion of direct deliveries is still quite small, and in most cases the delivery is outsourced.

\section{Summarised research results}

Based on this study of e-commerce platforms, it is possible to summarise that they can satisfy the basic needs of online sellers for logistics management, and the main findings can be represented in Table 1.

Table 1. E-commerce platforms and functionality coverage in the basic installations

\begin{tabular}{|l|l|}
\hline Customer relationship management & Functionality coverage \\
\hline $\begin{array}{l}\text { Relationship management with trade } \\
\text { partners }\end{array}$ & $\begin{array}{l}\text { Not fully supported in the basic installations but upgradable with } \\
\text { plugins/extensions }\end{array}$ \\
\hline $\begin{array}{l}\text { Integration with logistics service } \\
\text { providers and payment systems }\end{array}$ & $\begin{array}{l}\text { Integration support available with the leading logistics service } \\
\text { providers and payment systems } \\
\text { Additional upgrade is needed for local providers and systems }\end{array}$ \\
\hline Supplier relationship management & $\begin{array}{l}\text { Only some platforms offer built-in supplier relationship management } \\
\text { Upgradable/Low assortment of plugins available } \\
\text { Possible integration with ERP systems or addition of ERP capabilities } \\
\text { to the e-commerce platform }\end{array}$ \\
\hline $\begin{array}{l}\text { Integration of internal supply chain } \\
\text { processes }\end{array}$ & $\begin{array}{l}\text { Available with limited functionalities } \\
\text { Additional upgrades available for the basic inventory and } \\
\text { warehousing needs, mainly picking and labelling } \\
\text { Basic integration with barcode systems }\end{array}$ \\
\hline
\end{tabular}

Most of the e-commerce platforms are focused primary on the product's presentation in the web space and receiving orders, and not so much on the related logistics activities and their management in the supply chain.
Their main advantage is that they can be upgraded by using external extensions. This is a basic approach for most of the open-source products and it has many benefits. The market for such solutions is very competitive and 


\section{Articles}

online sellers have a great variety of software options to choose from, but unfortunately mainly in the field of marketing and limited to logistics. In general, there is no single solution that will fit all business needs because there are thousands of software solutions for uprating platforms and every one of them has its own specific focus. That is why the right combination has to be based on analysis of the supply chain management system.

\section{Conclusions and Future Research}

Modern e-commerce platforms are more than a software solution for presentation of the company products in the web space. Now they have real potential for their transformation into small-sized ERP systems which are not limited just to the organisation. They are open to the supply chain members and to online integration with their information systems which is a prerequisite for developing basic SCM practices in the supply chain and achieving better competiveness of supply chain members. This evolution stage of the e-commerce platforms is a signal for the appearance of alternatives for flexible SCM software solutions.

The current research does not cover all the topics related to e-commerce platforms. It is focused on the main framework and it could be used as a basis for other research projects for revealing detailed problems about e-commerce platforms and 1) integration with logistics service providers and 2) integration of the other transport, warehousing and inventory management systems used in the organisation. Another alternative for future research projects is to cover the integration of e-commerce platforms in the organisation and the level of usage of their functionalities for the automation of logistics processes.

\section{References}

Atanasov, B., 2016. Pricing in Omni-channels. In: Omni-channel trading and innovations. Publishing Complex - UNWE (in Bulgarian), pp. 151-155.

Augment, 2016. The Evolution of eCommerce Over the Last Decade [online]. Augment News. Available at: https://www.augment.com/blog/ evolution-ecommerce-last-decade/ [Accessed 10 January 2019].

BigCommerce Pty., 2019a. BigCommerce: Ecommerce Platform \& Shopping Cart Software [online]. BigCommerce. Available at: https://www.bigcommerce.com/ [Accessed 12 January 2019].

BigCommerce Pty., 2019b. What is logistics and how does it apply to ecommerce? [online]. BigCommerce. Available at: https://www. bigcommerce.com/ecommerce-answers/ what-logistics-and-how-does-it-applyecommerce/ [Accessed 12 January 2019].

Bowersox, D.J., Closs, D.J., Cooper, M.B., 2002. Supply chain logistics management. McGraw-Hill.

Boysen, N., de Koster, R., Weidinger, F., 2018. Warehousing in the e-commerce era: A survey [online]. European Journal of Operational Research. Available at: https://linkinghub. elsevier.com/retrieve/pii/S0377221718307185 [Accessed 10 January 2019].

BuiltWith, 2019. eCommerce technologies Web Usage Distribution [online]. Available at: https://trends.builtwith.com/shop [Accessed 12 January 2019].

Christopher, M., 2011. Logistics \& supply chain management 4. ed. Harlow: Financial Times Prentice Hall.

Cross, J., 2018. 5 Systems Integrations You'll Need For Successful B2B Ecommerce [online]. TechnologyAdvice. Available at: https:// technologyadvice.com/blog/sales/systems- 


\section{Articles}

integrations-b2b-ecommerce/ [Accessed 11 January 2019].

Dragomirov, N., 2014. Information systems in logistics. Sofia: Publishing complex - UNWE (in Bulgarian).

Dragomirov, N., 2015. Market-oriented Logistics in Bulgarian Trade and Manufacturing Enterprises. Economic Alternatives,

(4), pp.60-71.

Eurostat, 2017. E-commerce statistics - Statistics Explained [online]. Available at: https:// ec.europa.eu/eurostat/statistics-explained/index.php/E-commerce_statistics [Accessed 12 January 2019].

Evans, P.B., Wurster, T.S., 1997. Strategy and the new economics of information. Harvard Business Review, 75(5), pp.70-82.

Hayes, M., Youderian, A., 2013. The Ultimate Guide to Dropshipping 1st edition. Lulu Publishing Services.

HCL, 2014. API-fication Core Building Block of the Digital Enterprise [online]. Noida: HCL. Available at: https://www.hcltech.com/whitepapers/systems-integration/api-fication-corebuilding-block-digital-enterprise.

Hill, B., 2017. 9 Benefits of Magento eCommerce Platform [online]. CodeClouds. Available at: https://www.codeclouds.com/ blog/9-benefits-magento-ecommerceplatform-online-shopping/ [Accessed 12 January 2019].

Kadłubek, M., 2015. The Selected Areas of E-logistics in Polish E-commerce. Procedia Computer Science, 65, pp.1059-1065. 10.1016/j.procs.2015.09.052.

Kateva, M., 2017. Infrastructure and communications (in Bulgarian). The click\&collect delivery method as a trend in omni-channel retailing, 1, pp.14-31.

Kawa, A., 2017. Fulfillment service in e-commerce logistics. Logforum, 13(4), pp.429-438. 10.17270/J.LOG.2017.4.4.
E-Commerce Platforms and Supply Chain Management Functionalities Study

Kochubei, D., Lysa, S., 2018. Formation of a system of performance indicators for logistics in e-commerce. Scientific Bulletin of Polissia, 2(1(13)), pp.170-174. 10.25140/2410-95762018-2-1(13)-170-174.

Lambert, D.M., 2008. Supply Chain Management: Processes, Partnerships, Performance 3th ed. Supply Chain Management Institute.

Laudon, K.L.J.P., 2013. Management Information Systems, Global Edition 13th edition. Boston, Mass.: Pearson Education Limited.

Lim, S., Srai, J., 2015. Last-mile logistics models: A literature review and design guideline. In: 20th International Symposium on Logistics. Bologna, Italy.

Magestore, 2019. Magento Purchase Order Management [eBook]. Available at: https:// www.magestore.com/purchase-ordermanagement [Accessed 12 January 2019].

Nielsen, 2017. The Nielsen Global Connected Commerce Survey [online]. Available at: https://www.nielsen.com/content/dam/ corporate/us/en/reports-downloads/2017reports/nielsen-global-connected-commercereport-january-2017.pdf.

Noyes, K., 2010. 10 Reasons Open Source Is Good for Business [online]. PCWorld. Available at: https://www.pcworld.com/article/209891/10_reasons_open_source_is_ good_for_business.html [Accessed 13 January 2019].

Pirinsky, A., 2018. How To Scale Your E-Commerce Sales Pipeline By Integrating Systems [online]. Forbes. Available at: https://www. forbes.com/sites/forbescommunicationscouncil/2018/06/05/how-to-scale-your-e-commerce-sales-pipeline-by-integrating-systems/ [Accessed 6 February 2019].

PostNord, 2017. E-commerce in Europe [online]. Stockholm. Available at: https://www. 
postnord.com/en/media/publications/ecommerce/.

Prestashop, 2019. Third-party Data Integration (CRM, ERP...) - PrestaShop Modules [online]. Available at: https://addons.prestashop.com/ en/452-third-party-data-integrations-crm-erp [Accessed 13 January 2019].

Rakovska, M., 2011. Characteristics of supply chain management in Bulgaria. Research in logistics \& production, pp.93-104.

Rakovska, M.A., Stratieva, S.V., 2018. A taxonomy of healthcare supply chain management practices. Supply Chain Forum: An International Journal, 19(1), pp.4-24. 10.1080/16258312.2017.1395276.

Retail Sector Group of Enterprise Europe Network, 2018. A guide to e-commerce in Europe [online]. Available at: een.ec.europa. eu.

Richards, G., 2014. Warehouse Management: A Complete Guide to Improving Efficiency and Minimizing Costs in the Modern Warehouse Second edition. London: Kogan Page.

Saskia, S., Mareï, N., Blanquart, C., 2016. Innovations in e-grocery and Logistics Solutions for Cities. Transportation Research Procedia, 12, pp.825-835. 10.1016/j. trpro.2016.02.035.

Shopify, 2019. Start, grow, and scale your business [online]. Shopify. Available at: https:// www.shopify.com [Accessed 4 February 2019].
Statista, 2017. Top global e-commerce platforms market share 2017 [online]. Available at: https://www.statista.com/statistics/710207/ worldwide-ecommerce-platforms-marketshare/ [Accessed 4 February 2019].

Vakulenko, Y., Hellström, D., Hjort, K., 2018. What's in the parcel locker? Exploring customer value in e-commerce last mile delivery. Journal of Business Research, 88, pp.421-427. 10.1016/j.jbusres.2017.11.033.

Veeqo, 2018. Best Warehouse Management System [online]. Veeqo. Available at: https:// www.veeqo.com/features/warehousemanagement-system [Accessed 6 February 2019].

Wu, P.-J., Lin, K.-C., 2018. Unstructured big data analytics for retrieving e-commerce logistics knowledge. Telematics and Informatics, 35(1), pp.237-244. 10.1016/j. tele.2017.11.004.

Yu, Y. et al., 2016. E-commerce Logistics in Supply Chain Management: Practice Perspective. Procedia CIRP, 52, pp.179-185. 10.1016/j.procir.2016.08.002.

Zeng, L., Bolz, T., 2017. Analysis of the logistics efficiency in e-commerce online vs. multichannel. BIT, 1, pp.62-68.

Żurek, J., 2015. E-commerce influence on changes in logistics processes. Logforum, 11(2), pp.129-138. 10.17270/J.LOG.2015.2.1. 